\title{
Erratum to: Effects of Pulsed Laser Deposition Conditions on the Microstructure of $\mathrm{Ca}_{3} \mathrm{Co}_{4} \mathrm{O}_{9}$ Thin Films
}

\author{
TING SUN, ${ }^{1}$ HUEY HOON HNG, ${ }^{1,2}$ QINGYU YAN,${ }^{1}$ and JAN MA ${ }^{1}$ \\ 1.-School of Materials Science \& Engineering, Nanyang Technological University, Singapore \\ 639798, Singapore. 2.-e-mail: ashhhng@ntu.edu.sg
}

\section{Erratum to: Journal of ELECTRONIC MATERIALS \\ Vol. 39, No. 9, 2010, pp. 1611-1615 \\ DOI: 10.1007/s11664-010-1261-x}

In the above mentioned article, a reference for our previous work [1] was regrettably omitted. The authors sincerely apologize for this error.

The citations that should have been made are as follows:

1. Page 1612, Paragraph 1, Lines 1-2: “...formation of the $\mathrm{Ca}_{x} \mathrm{CoO}_{2}$ secondary phase in the thin films. ${ }^{1}$ The growth mechanism of ..."

2. Page 1613, Fig. 3 caption, Lines 2-3: “... under $20 \mathrm{~Pa}$ oxygen pressure at a substrate temperature of $750^{\circ} \mathrm{C}$. ${ }^{1}$ The peak at $33.24^{\circ}$ for the $5-\mathrm{Hz} . . "$
3. Page 1613, Paragraph 2, Lines 4-5: “... [1100] of the sapphire substrate on the cross-sectional area. ${ }^{1}$ Figure $4 a$ and $b$ shows ..."

4. Page 1614, Fig. 6 caption, last line: “... during thin-film growth. ${ }^{\text {" }}$

\section{REFERENCE}

1. T. Sun, J. Ma, Q.Y. Yan, Y.Z. Huang, J.L. Wang, and H.H. Hng, J. Cryst. Growth 311, 4123 (2009). doi:10.1016/j. jerysgro.2009.06.044. 